However, several points are important in this regard. First, to live up to scientific rigour the first part on 'the case-law' is indispensable. The body to be investigated must first be established - the facts, the data must first be collected and described, so to speak - before it can be discussed. A crucial step would be missed, if discussion and interpretation were begun right away. Uncertainty about the framework and the limits of the interpretation would result, ultimately rendering the study useless. Second, it cannot be avoided to be selective when it comes to interpretive formulas. Dozens of interpretive formulas are used in the body of case-law under scrutiny, a body of case-law that is, moreover, exceptionally large. It would fill many more volumes, if all of those formulas were to be traced. Third, given the need to select, variety is important. Hence, interpretive formulas are chosen that shed light on as many different aspects of the case-law as possible. The broad as well as the restrictive formulas discussed first in the second part elucidate the Court's activism to some extent and are potentially important beyond the law of the Union; the formula of coordination, which comes next, illuminates a possibly unique structural element in the Court's case-law; and the fundamental formula(s) partly reveal(s) how the case-law relies on hierarchy, in particular with regard to an 'institution' that is central to the Union, i. e. Union citizenship. The examination of this set of formulas, hopefully, allows us to achieve at least a better understanding of the Court's case-law in persons and services and of the way it evolves. Fourth, quite plainly, those interpretive formulas are traced in the case-law which, after years of careful study of the case-law, turned out to be most interesting. A personal element is, obviously, involved in this choice. But it is an informed choice and one the reader hopefully finds plausible.

\title{
IV A text-based approach
}

For all three interpretive formulas the analysis is based on the text of the decisions of the Court. This has two consequences. First, it is possible that some decisions escape scrutiny which, generally speaking, turn out to have a broad, sweeping character or implicitly rely on a coordinative or fundamental approach without that this is reflected in the wording of the decisions. Second, this book is not capable of fully answering the question why a specific formula is used in a decision. Factors outside the text of a decision influence the answer to the question 'why'. These factors include the composition of the Court, the opinion of the Advocate General, or the person who writes the decision. Such factors are not taken into account in this book because of the text-based approach. The book rather explains the 'when', the 'how', and to a certain extent the 'wherefore' for the relevant formulas. Yet, although the 'why' is ignored, the contribution this book makes is significant. As indicated above, the analysis of 'broad' formulas clarifies an aspect of the Court's activism, at least implicitly; the en- 
gagement with formulas of coordination sheds light on the structural nature of the Court's case-law; and the examination of 'fundamental' formulas helps us understand the hierarchy the Court injected into the law and its constitutional nature.

\section{$\mathrm{V}$ Why is this book useful and novel?}

The book for the first time gathers all the case-law of the Court on workers, citizens, establishment, services, diplomas, and social security. It does not just assemble the 'important' decisions, but all of them. ${ }^{1}$ This completeness is useful for the practitioner who is relieved of the worry that a relevant judgment escapes attention. The usefulness is not limited to this practical aspect though. The Union's law of social security has so far been a technical domain that has been left to the specialists. Consequently, there are mainly handbooks that are confined to explaining the basics of the Union's law of social security. ${ }^{2}$ Such handbooks sometimes also include international social security law; and they deal with the implications of international and Union law for a specific (member) state. ${ }^{3}$ Other items address just one aspect of social security. ${ }^{4}$ Shorter pieces regularly discuss the latest social security case-law of the Court. ${ }^{5}$ More profound contributions remain the exception. ${ }^{6}$ In scholarship the market freedoms of workers, service providers, and established persons exist entirely apart from social security. ${ }^{7}$ In

1 The book avoids drawing a distinction from the outset between 'important' and 'unimportant' decisions. Such a distinction would typically be drawn on the basis of the number of judges assigned to a case, thus distinguishing between grand and small chamber cases. However, the size of the chamber is plain data which is accessible through the Court's decision database. Given that, it seems exaggerated to add a further layer of complication to an already quite complex analysis. Quite apart from that, though, a distinction between 'important' and 'unimportant' decisions would be at odds with the aim of this book, which is to trace fully the evolution of certain interpretive formulas in the whole case-law examined. This aim basically implies that all cases are treated on an equal footing from the outset. An interpretive formula can then play a key role in a decision that is 'unimportant' in the greater scheme of things (and was e. g. assigned to a small chamber). In other words, from the perspective of interpretive formulas such a decision is indeed truly 'important', although it was decided by a small chamber. In brief, whether a decision is important or not for the evolution of interpretive formulas is to be decided in the light of the role an interpretive formula plays in this decision; 'importance' is an output of the investigation this book undertakes, rather than an input to it.

2 Robin C. A. White, EC Social Security Law (Harlow: Longman, 1999); Frans Pennings, European Social Security Law (Antwerpen: Intersentia, 2010); Eberhard Eichenhofer, Sozialrecht der Europäischen Union, 5. ed. (Berlin: Schmidt, 2013).

3 Bettina Kahil-Wolff and Pierre-Yves Greber, Sécurité sociale: aspects de droit national, international et européen (Basel: Helbing, 2006).

4 Yves Jorens and Bernd Schulte (eds), European Social Security Law and Third Country Nationals (Bruxelles: La Charte, 1998).

5 Vicki Paskalia, 'Co-ordination of Social Security in the European Union: An Overview of Recent Case Law', 46 Common Market Law Review (4) (2009), pp. 1177-1218.

6 One early exception was R. Lecourt, L'Europe des Juges (Brussels: Bruylant, 1976); later on, Robin C. A. White, Workers, Establishment, and Services in the European Union (Oxford: Oxford University Press, 2004); and Robin C. A. White, 'Social Solidarity and Social Security', in Anthony Arnull, Catherine Barnard, Michael Dougan and Eleanor Spaventa (eds), A Constitutional Order of States? (Oxford: Hart, 2011), pp. 301-319, are to be noted.

7 Take the edited volume Henry G. Schermers, Cees Flinterman, Alfred E. Kellermann, Johan C. von Haersolte and Gert Wim A. van de Meent f́ds), Free Movement of Persons in Europe (Dordrecht: Ni- 